\title{
0 óleo essencial de patchuli da Amazônia
}

\author{
M. Taveira Magalhāes $\left({ }^{*}\right)$ \\ P. Henriques Mendes (") \\ V. C. Wilberg (")
}

\begin{abstract}
Resumo
Relata-se um estudo comparativo feito entre amostras de óleo essencial de patchuli, oriundas de uma plantação experimental na Amazônia (Benfica, Belém, Pará) e amostras do mesmo óleo, normalmente comercializadas. Concluiu-se que, apesar das diferenças encontradas na composição química quantitativa e nas características olfativas, o óleo de patchuli produzido na Amazônia apresenta qualidades plenanente satisfatórias para a sua comercialização.
\end{abstract}

O óleo essencial de patchuli é há longos anos empregado em artigos finos de perfumaria, sendo matéria-prima de valor elevado. Dificilmente uma composição de fantasia, especialmente com uma "nota oriental" não contém uma boa percentagem de óleo de patchuli. Provém da destilação, por arraste a vapor, das folhas da espécie botânica Pogostemon cablin Benth. (sin. Pogostemon patchouli Pellet. var. suavis Hook.), família Labiatae. A planta é originária da Ásia tropical, sendo principalmente cultivada na Malásia (Cingapura) e na Indonésia (ilha de Sumatra). Por muito tempo exportavam-se as folhas secas e compactadas em fardos para a destilação na Europa e América do Norte. Devido ao seu valor, a planta foi introduzida na África (Madagáscar, ilha da Reunião e ilhas Seychelles) e América do Sul (Paraguai e Brasil (São Paulo, Mato Grosso e Amazônia)) em experiências de razoável sucesso ou de completo fracasso. Além da técnica especial de secagem e armazenagem das foihas e do processo de extração do óleo, modificaçỗes na morfologia e na composição química da planta devem ocorrer por influência do clima, solo e forma de cultivo.

Apesar da importância comercial do óleo e dê muitas tentativas feitas, durante muitos anos, o esclarecimento da composição quími- ca do óleo de patchuli foi um desafio cos químicos, pouco mais se sabendo que cerca de $97 \%$ do óleo consistia de compostos, na sua maioria sesquiterpênicos, que pouca influência tinha nas suas peculiares características olfativas (Guenther, 1949). Somente com os trabalhos de Bates et al. (1962) e principalmente de Tsubaki et al. (1967), esciareceramse a maioria dos constituintes do óleo de patchuli. Tais constituintes são: Hidrocarbonetos terpênicos: $\propto$-pineno, $\beta$-pineno, limoneno e canfeno.

Hidrocarbonetos sesquiterpênicos: $\beta$ - elemeno, cariofileno, $\propto-$ patchuleno, $\beta-$ patchuleno, $\propto-$ guaieno, $\propto$ bulneseno, alloaromadendreno e $\propto-$ gurjuneno.

Alcool sesquiterpênico: alcool patchulico.

Peyron (1972), em trabalho sobre o óleo essencial de patchuli produzido em Mato Grosso, menciona ainda a presença de $\lambda$ patchuleno, sem esclarecer sua estrutura.

Fiecentemente, a Secretaria de Agricultura do Estado do Pará, em colaboração com a Seção de Plantas Tropicais da CATI (Secretaria de Agricultura de São Paulo), elaborou um projeto para uma agroindústria de óleo essencial de patchuli, no qual se prevê o plantio inicial de 250 hectares. A plantação destinada a servir de matriz para a multiplicação por estacas. localiza-se em Benfica, perto de Belém. Originou-se de um pequeno número de estacas oriundas de um país asiático não conhecido, trazidas por uma firma japonesa que há muitos anos teve interesse no assunto. O plantio inicial ocorreu no Amazonas, porém foi transferido para o Pará, em virtude do melhor regime de chuvas.

Para avaliar as possibilidades de sucesso do produto brasileiro, além dos problemas re-

(*) - Centro de Tecnologia Agrícola e Alimentar, EMBRAPA, Rio de Janeiro. 
lativos à qualidade da planta matriz e do seu comportamento na região de cultivo atual, têm sido feitas experiências para estabelecer as condições de coleta e secagem das folhas, bem como da técnica adequada à destilação a vapor do óleo.

O presente trabalho relata os resultados de um estudo comparativo entre três amostras de óleo de patchuli obtido a partir da cultura experimental de Benfica e três amostras de óleo de patchuli alienígeno e importado para comercialização regular. O estudo comparativo foi feito através da determinação de constantes físicas e químicas (densidade, índice de refração, rotação ótica, índice de acidez e índice de ester), Tabela I; solubilidade em alcool, Tabela II; análise por cromatografia gás-í́quido, Tabela III; espectrometria no Infravermelho e avaliação olfativa.

As amostras do óleo brasileiro resultaram da extração de folhas postas a secar em prateleiras de amianto, construídas dentro de un galpão ventilado, inteiramente à sombra.

Amostra A - Obtida no Instituto Agronô. mico de Campinas (Seção de Plantas Aromáticas e Fumo), por arraste a vapor em alambique industrial. Foram processados 69 quilos de planta, durante 6 horas de destilação, com rendimento de $3,43 \%$.

TABELA I

Óleo Essencial de Patchuli

f N D I CES

\begin{tabular}{|c|c|c|c|c|c|c|c|}
\hline \multirow[b]{3}{*}{ d $\begin{array}{r}25 \\
25\end{array}$} & \multicolumn{3}{|c|}{ Amostras do Pará } & \multicolumn{3}{|c|}{ Amostras comerciais } & \multirow[t]{2}{*}{ Limites (Guenther) } \\
\hline & $\mathbf{A}$ & B & C & $\mathbf{D}$ & $\mathbf{E}$ & $\mathbf{F}$ & \\
\hline & 0,9487 & 0,9783 & 0,9746 & 0,9403 & 0,9374 & 0,9535 & $0,95 / 0,99$ \\
\hline n $\frac{25}{D}$ & 1,5081 & 1,5121 & 1,5111 & $i, 5061$ & 1,5030 & 1,5073 & $1,506 / 1,516$ \\
\hline$\propto \frac{25}{D}$ & $-49,3^{\circ}$ & $-61,5^{\circ}$ & $-65,2^{\circ}$ & $-66,4^{\circ}$ & $\cdots$ & $-52,0^{\circ}$ & $-40^{\circ} /-72^{\circ}$ \\
\hline $\begin{array}{l}\text { índice } \\
\text { acidez }\end{array}$ & 1,09 & 3,27 & 1,74 & 3,58 & 3,42 & 5,31 & $0,5 / 3,0$ \\
\hline $\begin{array}{l}\text { indice } \\
\text { ester }\end{array}$ & 4,2 & 9,6 & 5,5 & 7,5 & 6,8 & 8,0 & $2,0 / 10,0$ \\
\hline
\end{tabular}

TABELA II

Oleo Essencial de Patchuli SOLUBILIDADE EM ÁLCOOL

Amostras do Pará:

Amostra A - Turvo até 8 partes de álcool a $90^{\circ}$; levemente turvo até 10 partes; claro até 14 partes e solúvel em 16 partes.

Amostra B - Solúvel em 1 parte de álcool a $90^{\circ}$.

Amostra C - Claro em 1 parte de álcool a $90^{\circ} \mathrm{e}$ solúvel em 2 partes.

Amostras Comerciais:

Amostra D - Turvo até 14 partes de álcool a $90^{\circ}$; levemente turvo até 22 partes; claro após 24 partes.

Amostra E - Turvo até 6 partes de álcool a 90\%; levemente turvo até 16 partes; claro 17 paries.

Amostra F - Turvo até 6 partes de álcool a $90^{\circ}$; levemente turvo até 10 partes; claro em 12 partes.
Amostra B - Obtida no Centro de Tecnologia Agrícola e Alimentar, por arraste a vapor em alambique piloto de aço inoxidável. Foram processados 4 quilos de planta, durante 12 horas de destilação, com rendimento de $3,80 \%$.

Amostra C - Obtida no Centro de Tecnologia Agrícola e Alimentar, por arraste a vapor, com coobação das águas destiladas, em aparetho de vidro. Foram processados 8 quilos de planta, em partidas de 1 quilo cada, durante 10 horas de destilação, com rendimento de 3,81\%.

Amostra $D$ - "óleo de patchuli - Cingapura", proveniente da Phepo S.A.

Amostra E - "óleo de patchuli - Escuro - N. York", proveniente da I.F.F. Essências e Fragrâncias Ltda. 
TABELA III

Oleo Essencial de Patchuli

CROMATOGRAFIA GASS-LIQUIDO

COMPOSIÇAOO PERCENTUAL POR AREA DO CROMATOGRAMA

\begin{tabular}{crrrrrr} 
& \multicolumn{4}{c}{ Amostras do } & Pará & \multicolumn{3}{c}{ Amostras Comerciais } \\
Pico n. & \multicolumn{1}{c}{ A } & B & \multicolumn{1}{c}{ C } & D & E & F \\
1 & 2,2 & 2,1 & 1,9 & 1,5 & 2,1 & 0,7 \\
2 & 22,2 & 12,6 & 11,3 & 34,5 & 32,1 & 30,6 \\
3 & 20,9 & 13,9 & 10,8 & 17,6 & 24,4 & 18,9 \\
4 & 20,3 & 14,4 & 13,0 & 13,3 & 9,6 & 15,2 \\
5 & 3,0 & 3,8 & 2,6 & 3,1 & 3,7 & 1,9 \\
6 & 1,7 & 3,2 & 1,9 & 1,7 & 0,9 & 0,9 \\
7 & 4,8 & 7,7 & 7,1 & 7,3 & 4,3 & 6,2 \\
8 & 23,6 & 31,3 & 45,9 & 17,4 & 16,0 & 21,3
\end{tabular}

Picos: $\beta-$ patchuleno (1); $\alpha-$ guaieno e cariofileno (2); allo-aromadendreno e $\propto-$ patchuleno (3); $\alpha$ - bulneseno (4); năo identificados $(5,6,7)$; álcool patchulico (8).

Cromatógrafo modelo CG-15 (condutividdae térmica); Coluna de $20 \%$ de Carbowax $20 \mathrm{M}$ em Cromosorb W, comprimento $2 \mathrm{~m}$, diâmetro interno $1 / 4$ "; temperatura da Coluna $180^{\circ} \mathrm{C}$; temperatura do vaporizador $280^{\circ} \mathrm{C}$; temperatura do detector $296^{\circ} \mathrm{C}$.

Amostra F - "óleo essencial de patchuli - Claro, Rio", proviente da I.F.F. Essências e Fragrâncias Ltda.

As constantes físicas e químicas do óleo brasileiro situam-se entre os limites estabeiec:dos para o óleo de patchuli. A solubilidade em alcool não representa uma avaliação muito bem definida. A análise por cromatografia gás-líquido evidencia boa semelhança entre as amostras $A$ (IAC) e $D$ (Cingapura) e $F$ (óleo claro). A amostra $C$, obtida per coobação das águas destiladas, apresenta um grande teor de alcool patchulico (componente mais pesado) e menor percentagem de frações mais leves. seguramente devido ao maior tempo de extração. Os espectros no Infravermeiho são qualitativamente idênticos, mostrando variações nas intensidades relativas das bandas, em função das diferenças percentuais dos componentes. Finalmente, a avaliação olfativa revela para o óleo brasileiro uma certa conotação "verde", com uma nota de fundo de "cedro", mais próxima da amostra $F$ (óleo claro), provavelmente devido ao pouco tempo de maturação das foIhas após a secagem e à pouca idade do óleo.

Apesar de que sensiveis variações nas características do óleo podem resultar da técnica de secagem das folhas e processamento extrativo do óleo, quer nos parecer que a planta aclimatada no Pará tenha sofrido razoáveis modificações. Todavia, a qualidade do óleo que pode ser obtido, tendo em vista as análises reaiizadas e as avaliações feitas por diversas firmas que comercializam óleos essenciais no Brasi!, parece ser suficientemente satisfatória para permitir a sua comercialização com sucesso, evitando, pelo menos em parte, um maior consumo de óleo importado. Dependendo de precos e demanda do mercado internacional, poderá, inclusive, conquistar o mercado exterior.

\section{Agradecimentos}

Agradecimentos pela cessão de amostras. são devidos aos Drs.: Mario Guilherme Roberto Donalisio e Alcides d'Andrea Pinto, Instituto Agronômico de Campinas; Guilherme de C.B. Paixão, I.F.F. Essências e Fragrâncias Ltda. e José Maria Pinheiro Condurú, Secretária de Agricultura do Estado do Pará.

\section{SUMMARY}

Three samples of oil of patchouly produced experimentally at Benfica, near Belém, Pará, Brasil, and three samples of commercial imported oil of patchouly were compared through physical constants, solubility in ethanol, gas chromatographic and infrared spectrometric analysis, as well olfactory evaluation. The results indicate that although some differences exist in the chemical composition, the value in perfumery for all brazilian samples are good for commercial exploitation.

\section{BIBLIOGRAFIA CITADA}

BATES, R.B. ET AL

$$
\begin{aligned}
& 1962-\beta-\text { Bulnesene, } \alpha-\text { Guaiene, } \beta- \\
& \text { Patchoulene and Guaioxíde in Essential } \\
& \text { Oils. Chem. \& Ind., 1715. }
\end{aligned}
$$

GUENTHER, E.

1949 - The Essential Oils. New York, D. Van Nostrand Comp. v. 3, p. 552.

PEYRON, L.

1972 - Sur Queloues Essences en provenance du Mato Grosso. Anais Acad. brasil. ciênc., 44, (suplemento) : $332-\mathrm{V}$ International Congress of Essencial Oils, Brazil.

TSUBAKI, N. ET AI

1967 - Hydrocarbons in Patchouli Oil. Bull. Chem. Soc. Japan, 40:597. 